\title{
LXXXI. On a new method of preparing iodous acid
}

\section{Lewis Thompson Esq.}

To cite this article: Lewis Thompson Esq. (1836) LXXXI. On a new method of preparing iodous acid, Philosophical Magazine Series 3, 9:56, 442-443, DOI: 10.1080/14786443608649037

To link to this article: http://dx.doi.org/10.1080/14786443608649037

册 Published online: 01 Jun 2009.

Submit your article to this journal 준

Џ Article views: 2

Q View related articles $\sqsubset$ 
LXXXI. On a new Method of preparing Iodous Acid. By Lewis Trompson, Esq., Member of the Royal College of Surgeons.

To the Editors of the Philosophical Magazine and Journal. Gentlemen,

I SEND you a new method of preparing iodic acid; it is $I$ cheaper and safer than the process of Sir HumphryDavy, and affords a purer acid than the plan pursued by Gay-Lussac. I say purer, because from some experiments which I have lately made, and intend to repeat more carefuily, 1 am led to conclude with Sir Humphry Davy, that the acid of GayLussac is sulpho-iodic acid.

\section{Process, for preparing Iodic Acid.}

Put one atom or 126 grains of iodine into a proper bottle with 24 ounces of water, and pass chlorine, previously washed in cold water, through the mixture until it shall have become colourless; set the solution aside for an hour; then heat it to $212^{\circ}$ Fahr., to disengage the uncombined chlorine, and add $2 \frac{\mathrm{T}}{2}$ atoms or 295 grains of recently precipitated oxide of silver; boil the whole for ten minutes, filter, and evaporate carefully to dryness : the product is pure anhydrous iodic acid.

It will be at once perceived by the above process that there is no such acid as the chloriodic, the acid so called being in fact merely a chloride of iodine, which when dissolved in water is converted into muriatic and iodic acids, with a variable quantity of iodine. How this mistake can have passed so long unnoticed is to me a matter of surprise; at the same time I must observe that I have not been able to unite chlorine and iodine in the proportions necessary to form these acids without the intervention of water; there is always an excess of iodine: but $I$ have no doubt that this may be effected in a sufficiently reduced temperature. In the last experiment which I made on this subject 50 grains of iodine combined with 41.5 cubic inches or about 30 grains of chlorine: the substance thus formed when put into a large quantity of water, and exposed for some days to the sunshine, deposited 8 grains of iodine and became of a pale yellow colour.

That the muriatic and iodic acids exist ready formed in the solution I am confident, not only from the taste and smell, but because I have obtained free muriatic acid from it by distillation, although when this is continued until the solution becomes a good deal concentrated, these acids react upon each other and produce chlorine and iodine. 
As the iodate of ammonia is not noticed in any work with vhich I am acquainted, I think it right to observe here that it is a highly crystalline granular powder, possessed of but little solubility: it may be prepared by saturating the solution of the muriatic and iodic acids with pure ammonia, when it will fall down, the muriate remaining dissolved. I find that iodic acid is decomposed by sulphocyanic acid and the sulphocyanates of potash and soda; and also that saliva, in consequence probably of the sulpho-cyanate of potash it contains, decomposes iodic acid, and produces with it and starch a blue precipitate not to be distinguished from that produced under similar circumstances by morphia. The importance of this discovery in a medico-legal point of view is considerable, since iodic acid is now very much relied upon as a test for morphia. I am, Gentlemen, yours, \&ic.

Roebuck Place, Great Dover Road, Southwark.

LEWIS Thompson, M.R.C.S.

LXXXII. Explanation of a remarkable Paradox in the Calculus of Functions, noticed by Mr. Babbage. By Joн N T. Graves, Esq., M.A., of the Inner Temple.

[Continued from p. 34], and concluded.]

HAVING thus proved that

$$
e_{0} \sqrt{-1} \frac{z}{\sqrt{z^{2}}} \cos _{0+1}^{-1} \frac{y}{\sqrt{y^{2}+z^{2}}}=\frac{y+\sqrt{-1} z}{\sqrt{y^{2}+z^{2}}},
$$

we have seen in what manner it follows that

is an $e-\log$ of $x$. Q. E. D.

$$
l \sqrt{y^{2}+x^{2}}+\sqrt{-1} \frac{2}{\sqrt{z^{2}}} \cos _{0+}^{-1} \frac{y}{\sqrt{y^{2}+z^{2}}}
$$

Let $l \sqrt{y^{2}+z^{2}}+\sqrt{-1} \frac{z}{\sqrt{z^{2}}} \cos ^{-1} \frac{y}{\sqrt{y^{2}+z^{2}}}$ (which I call the $0^{\text {th }} e$-log of $x$ of the $0^{\text {th }}$ order) be denoted by $l(y+\sqrt{-1} z)$ or $l x$. It is plain that when $x$ is real and positive, $l x$ resolves itself in point of quantity (as it ought to do, if our notation be consistent) into the arithmetical $e-\log$ of $x$. Following the same notation,

$$
l \frac{1}{\sqrt{y^{2}+z^{2}}}-\sqrt{-1} \frac{z}{\sqrt{z^{2}}} \cos _{0+1}^{-1} \frac{y}{\sqrt{y^{2}+z^{2}}}
$$

$3 \mathrm{G} 2$ 